\title{
Optimization of transesterification process and characterization of biodiesel from soapstock using silica sulfuric acid as a heterogeneous solid acid catalyst
}

\author{
Samuel Latebo*, Abreham Bekele**, Temesgen Abeto** and Job Kasule*** \\ * School of Chemical Engineering, Wollo University, Combolicha Campus, Dessie, Ethiopia \\ ** School of Chemical Engineering, Jimma Institute of Technology, Jimma University,Jimma, Ethiopia \\ *** Texas Tech University, Post-Doctoral research associate and Post Doctoral Fellow at West Virginia University, USA \\ * Corresponding Author: samuellatebo@gmail.com
}

Submitted : 17/10/2020

Revised :09/06/2021

Accepted :20/06/2021

\begin{abstract}
The main objective of this study was production, optimization, and fuel quality characterization of biodiesel from equal weight ratio blended acid oil of cottonseed and sunflower soapstock using silica sulfuric acid as a solid acid catalyst in laboratory scale. The physicochemical properties of soap stock samples and extracted acid oil from each soap stock were determined. The experiment was designed by design expert (version 11) software. The 5-level 4 factors (methanol to acid oil molar ratio, catalyst weight, stirring rate, and reaction time) were designed using the central composite design method. From the experimental results, the maximum biodiesel yield of $90.68 \%$ was obtained using methanol to acid oil molar ratio of 7:1 using catalyst $5.5(\% \mathrm{wt} / \mathrm{wt})$ with a stirring rate of 300rpm at $3 \mathrm{hr}$ reaction time. The average value of triplicate experiment of biodiesel yield from the experimentation at optimized condition was $92.62 \%$. The analysis of variance results indicated that satisfactory results were achieved. The carried out physiochemical properties of produced biodiesel were within a range and some were closest to American and European biodiesel standards.
\end{abstract}

Keywords: Biodiesel; Cottonseed soapstock; Optimization; Silica sulfuric acid catalyst; Sunflower soapstock.

\section{INTRODUCTION}

Recently, the energy crisis on the global level is rapidly increasing because of the large amount of energy consumption among the worldwide population and due to fast economic development (Nejat et al., 2015). The dominant energy sources in the world are fossil fuels. The main drawback of fossil fuels is that they generate greenhouse gases (GHGs). The GHGs result in the environment becoming warmer and cause unpredictable and dramatic changes in climatic conditions. Limited primary energy sources and negative impacts of fossil fuels on the environment and health of humans have driven the glob's attention towards sustainable energy sources (Bilgen and 
Reviews, 2014). Biodiesel is one of the alternatives and sustainable energy sources. It is composed of mono-alkyl esters. It attracted increased attention due to its biodegradability, renewability, and less toxicity (Hanjra and Qureshi, 2010). It can be produced from edible vegetables' oil, nonedible vegetables' oil, animals' fats, and oils, and waste greases or waste cooking oil (Ashraful et al., 2014).

In some reported work, $\mathrm{H}_{2} \mathrm{SO}_{4}$ is used as a homogeneous acid catalyst for the esterification of soapstock AO to esters. But $\mathrm{H}_{2} \mathrm{SO}_{4}$ is not capable of completely conversing FFA to esters even after 26h. As an alternative, enzyme catalyst and heterogeneous acid catalysts (Pathak and Pereira, 2016) have been investigated and reported by the researchers. However, there was a gap in simultaneous esterification and transesterification of soapstock AO using advantageous heterogeneous catalysts. Silica sulfuric acid (SSA) is a solid acid catalyst. Its catalytic performance was demonstrated in many organic reactions. It has superability to donate protons due to its high acid cites. This catalyst has the advantage of low cost, is easy to prepare, is reusable, and makes the reaction fast (Amoozadeh and Rahmani, 2015). Optimization of the simultaneous esterification and transesterification for biodiesel production from equal weight-to-weight ratio blended AO obtained from cottonseed and sunflower soapstock using SSA catalyst is the main objective of the present study.

\section{METHODOLOGY AND EQUIPMENT DESIGN}

The raw material for biodiesel production in this study was soapstock of cottonseed and sunflower that was obtained from the Addis Modjo Edible oil refining industry in Addis Ababa, Ethiopia. Chemicals and reagents: sulfuric acid (purity, 98\%), methanol (purity, 99.8\%), distilled water, dimethyl ether, ethanol, petroleum ether, potassium hydroxide, sodium hydroxide, hydrochloric acid, phenolphthalein indicator, and acetone were used.

Cottonseed and sunflower are the most dominant feedstocks for edible oil production in this oil processing industry. The potential source of reset ones is low. The industry operated in continuous operation mode, and the formed soapstock separated from crude oil within centrifuge separators by continuous washing. More than $95 \%$ of soapstock separated at the first centrifuge separator, and the rest of three centrifuges separated a very less amount of soapstock with a high amount of water content. The second centrifuge re-refines the remaining soapstock from crude oil. The third and the fourth centrifuges are used for washing purposes to remove any impurities left in the oil. Soapstock samples after collection from the oil refining industry were stored in dark atmospheric conditions. When storing the samples, careful handling is required to avoid composition change. The soapstock samples can remove their moisture easily when exposed to unsustainable storing conditions that can lead to change in their compositions.

\section{PREPARATION OF SILICA SULFURIC ACID CATALYST}

The SSA catalyst was prepared according to the procedure used in the reported work (Deng et al., 2010). The SSA catalyst was prepared by sulfonation of silica gel (60-120 mesh) with $\mathrm{H}_{2} \mathrm{SO}_{4}$. $40 \mathrm{~g}$ of a slurry of silica gel was taken and placed in a $500 \mathrm{ml}$ beaker. Then, $200 \mathrm{ml}$ of diethyl ether was added into the sample holder beaker. Then, $12 \mathrm{ml}$ of $\mathrm{H}_{2} \mathrm{SO}_{4}$ was slowly added to the mixture. After $\mathrm{H}_{2} \mathrm{SO}_{4}$ was added, the sample holder beaker was covered with aluminum foil. The solution was well shaken for 5 minutes to distribute the $\mathrm{H}_{2} \mathrm{SO}_{4}$ in the whole surface of the silica gel with the help of diethyl ether. After shaking, the sample mixture was placed on a water bath that operated at $36^{\circ} \mathrm{C}$ above the boiling point of diethyl ether. The diethyl ether was slowly evaporated from the solution mixture. The remained sample was allowed to dry at atmospheric conditions. Two more similar experiments were conducted. The sulfonation reaction was shown as follows in (R-3.1). 


$$
\mathrm{SiO}_{2}-\mathrm{OH}+\mathrm{OH}-\mathrm{SO}_{3} \mathrm{H} \longrightarrow \mathrm{SiO}_{2}-\mathrm{OSO}_{3} \mathrm{H}+\mathrm{H}_{2} \mathrm{O}
$$

\section{LABORATORY SCALE BIODIESEL PRODUCTION/EXPERIMENTAL DESIGN}

The design expert (version 11) software was used to design the experiment and to carry out optimization. From the Response Surface Method (RSM), the Central Composite Design method (CCD) was applied to the design experiment. The CCD with the rotatable feature was employed to design the experiment with four important process variables (methanol to AO molar ratio, catalyst weight, stirring rate, reaction time, and reaction time) at five levels. The designed experiment was a total of 30 experiments. From total experiments, 6 experiments were replications at the center point of each factor. The upper and lower values of the four factors were available in Table 1 . The experiments were carried out according to a randomly distributed run order designed by CCD.

Table 1. Design factors with their lower and upper values.

\begin{tabular}{|l|c|c|}
\hline \multirow{2}{*}{ Factors } & \multicolumn{2}{|c|}{ Replication, 6 times at center points } \\
\cline { 2 - 3 } & Minimum value & Maximum value \\
\hline Methanol to acid oil molar ratio & $4: 1$ & $10: 1$ \\
\hline Catalyst weight (wt \%) & 3 & 8 \\
\hline Stirring rate (rpm) & 200 & 500 \\
\hline Reaction time (hr.) & 2 & 4 \\
\hline
\end{tabular}

\section{Biodiesel Production Procedures}

Biodiesel production from soapstock is different from other feedstocks, because the soapstock AO contains high FFA and a small amount of NO. The esterification reaction is the major reaction in the production of biodiesel from soapstock AO. Transesterification is also needed in this process to convert NO part into fatty acid mono-alkyl esters. In this work, simultaneous esterification and transesterification reactions were performed using the SSA catalyst. The biodiesel production was operated in a batch process. The first SSA catalyst and methanol were mixed. Then, AO and mixture of catalyst and methanol were added into a $250 \mathrm{ml}$ conical flask. The magnetic stirrer was inserted into the sample containing flask, and the flask was well equipped with aluminum foil. Then, the conical flask placed on heating mantle operated at $60^{\circ} \mathrm{C}$ with rigorous mixing. After the end of reaction time, the mixture was allowed to settle in separator funnel. Phase separation started within $10 \mathrm{~min}$, and for complete phase separation, it took about $4 \mathrm{hr}$. The top layer was biodiesel, and the bottom was a mixture of impurities, mainly water and catalyst. The catalyst was separated from the bottom phase through filtration. The separated biodiesel was washed by hot at $80^{\circ} \mathrm{C}$ distilled water $\left(3 \% \mathrm{v} / \mathrm{v}\right.$ of biodiesel) two times to remove impurities. The purified FAMEs were dried on a hot plate at $105^{\circ} \mathrm{C}$ for $30 \mathrm{~min}$. This process applied to all experiments as shown in figure 1. 

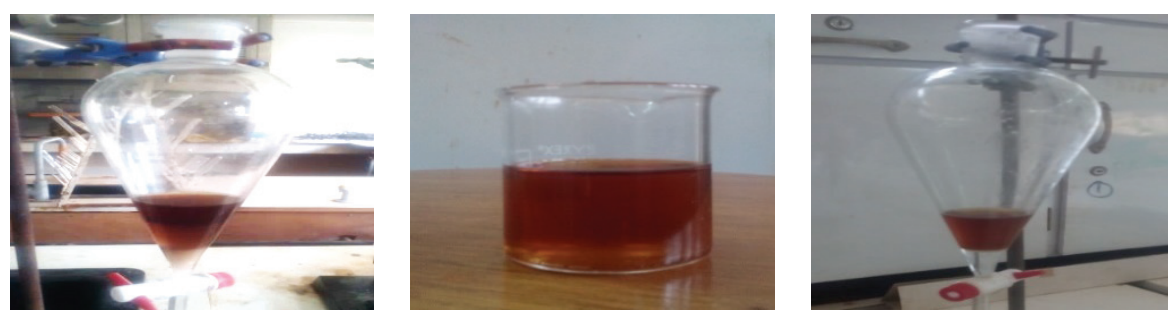

Figure 1. Phase separation and purification of biodiesel.

\section{RESULT AND DISCUSSION}

\section{Catalyst Characterization}

FTIR spectroscopy is used to determine the functional groups of the catalyst after and before modified. IR spectra of silica gel and SSA catalysts were shown in Figure 2. The spectroscopic analysis was carried out within a wave number from $4000-400 \mathrm{~cm}^{-1}$. The absorption bands of SSA and silica gel from Figure 2 were recorded, and their corresponding entire bonds with vibration mode were available in Table 2.

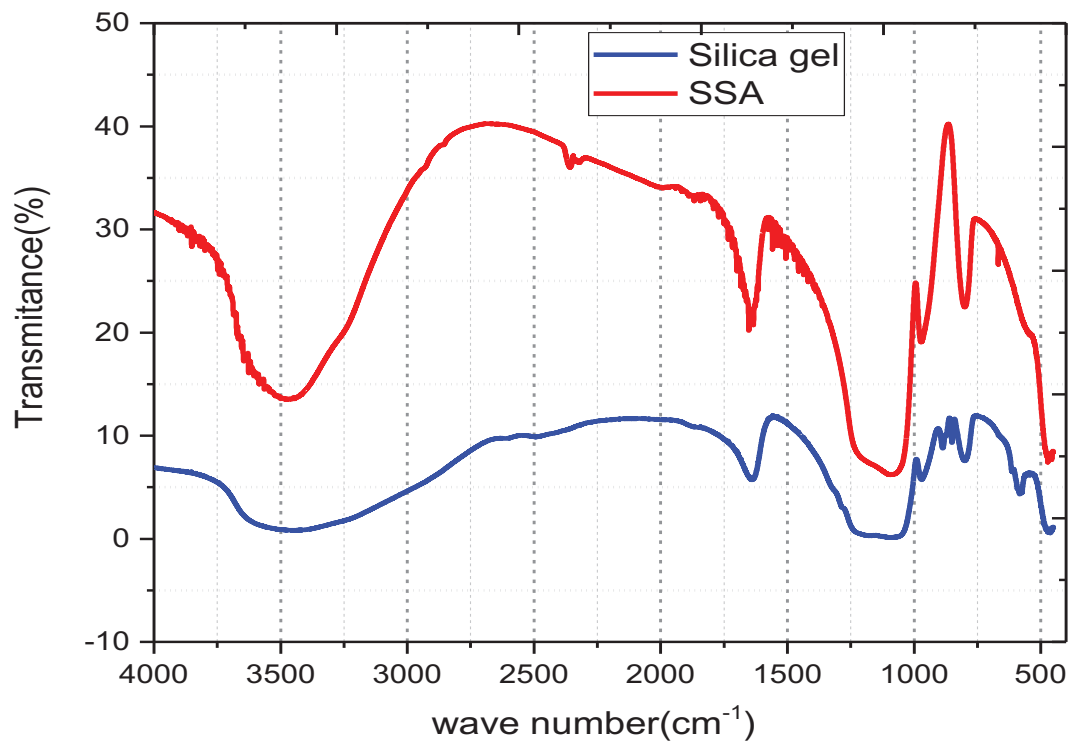

Figure 2. FTIR spectra of fresh silica gel and silica sulfuric acid catalyst.

FTIR spectra of fresh silica gel and SSA in Figure 2 indicate a significant change between the two graphs. The major absorption peaks of fresh silica gel were at $500-1000 \mathrm{~cm}^{-1}$ (Si-O vibration modes), $1000-1200 \mathrm{~cm}^{-1}$ ( $\mathrm{Si}-\mathrm{O}$ Si stretching bands), 1643.5 (OH stretching), and 3400-3600 (OH bending vibration), whereas FTIR spectra of SSA were at $1100-1230$. The absorption band indicates the overlap of $\mathrm{Si}-\mathrm{O}$ stretching and $\mathrm{O}=\mathrm{S}=\mathrm{O}$ stretching modes. In addition, the absorption at 2356.1 shows the sulfonic group attached to the SSA catalyst. This confirmed the presence of the sulfonic group on the surface of the SSA catalyst. The FTIR spectra of the SSA catalyst demonstrated similar features with the literature reported (Aldana et al., 2013). The detailed information is available in Table 2. 
Table 2. Absorption bands and corresponding vibrations/functional group of SSA and fresh silica gel.

\begin{tabular}{|l|l|l|}
\hline \multirow{2}{*}{$\begin{array}{l}\text { Wave number } \\
\left(\mathrm{cm}^{-1}\right)\end{array}$} & Vibration mode & Silica sulfuric acid \\
\cline { 2 - 3 } & Silica gel & O-H(bending vibration) \\
\hline $3400-3600$ & O-H (bending vibration) & H-O-S = O (Sulfonic group) stretching \\
\hline 2356.1 & --- & \\
\hline 1643.5 & O-H(stretching) & Si-O-Si (stretching) \\
\hline $1039-1229$ & Si-O (stretching) & O=S=O and Si-O(overlap) stretching \\
\hline $500-1000$ & Si-O (stretching) & $\begin{array}{l}\text { Si-O and Si-O-Si stretching and bending } \\
\text { and bending) }\end{array}$ \\
\hline
\end{tabular}

\section{Powder XRD Characterization of Catalyst}

Powder XRD characterization of the catalyst was performed. XRD patterns of SSA and fresh silica gel were shown in Figure 3. XRD patterns of both SSA and silica gel demonstrated similar features. In XRD patterns, there was a broadband peak in two-theta (22.5 degrees) that confirmed the amorphous nature of the silica gel and SSA catalyst. The XRD pattern similarity of SSA with that of silica gel shows that the amorphous nature of the catalyst was not alerted after the introduction of the sulfonic group. This was in agreement with the literature, in which sulfonated silica gel and fresh silica gel demonstrated similar XRD patterns (Balachandran et al., 2017).

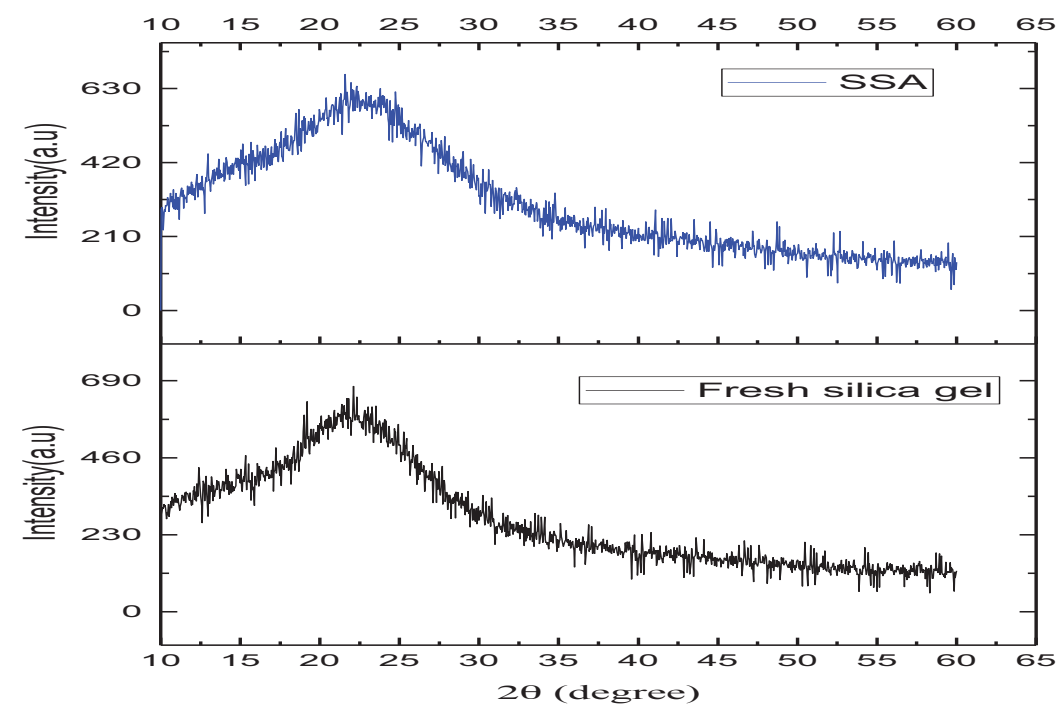

Figure 3. Powder XRD patterns of fresh silica gel and silica sulfuric acid catalyst. 


\section{Thermogravimetric Characterization of Catalyst}

The prepared SSA catalyst was subjected to the thermal stability analyses by thermogravimetric analysis (TGA). Analyzing the thermal stability of the catalyst is important to determine the catalyst's thermal stability. Thermal degradation and percent weight loss of the catalyst are shown in Figure 4. Figure 4a represents the thermal degradation of the SSA catalyst with increasing temperature. The initial sample weight was $50.17 \mathrm{mg}$, which was slowly degraded with increasing temperature. The percentage of weight loss with increasing temperature is illustrated in Figure $4 b$.
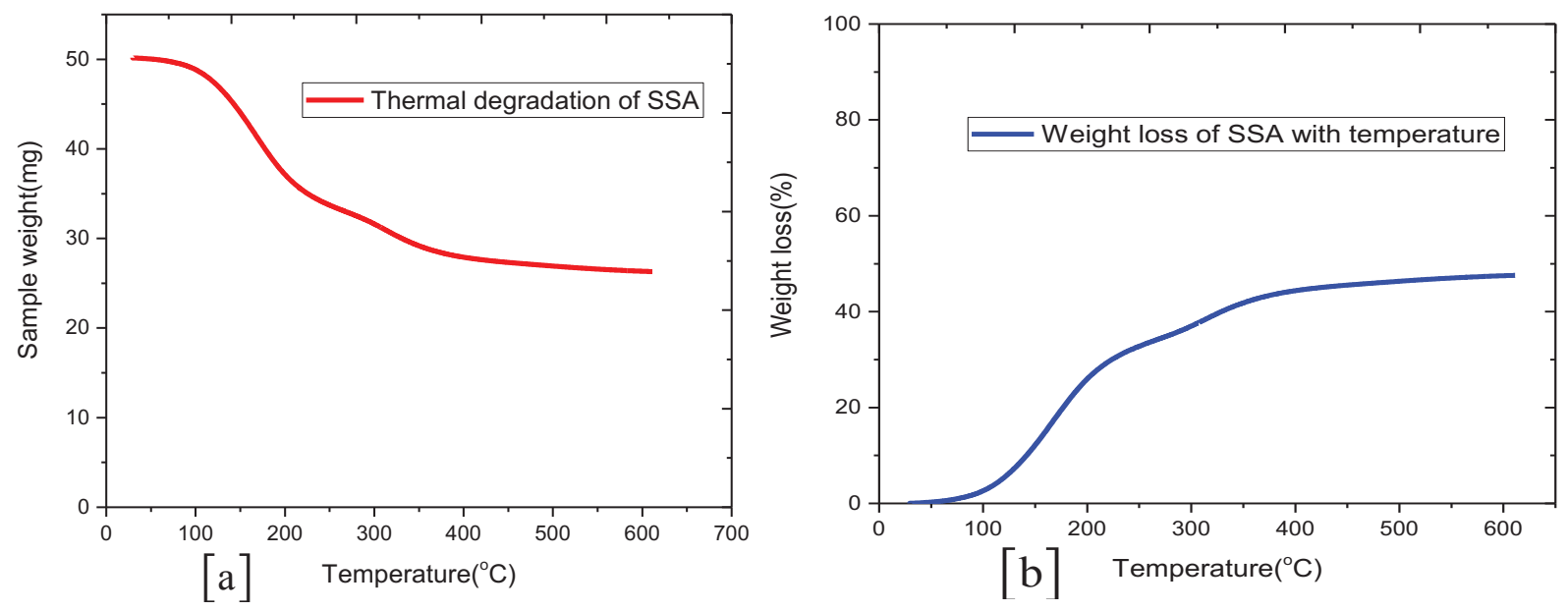

Figure 4. TGA profile of the silica sulfuric acid catalyst.

SSA catalyst was almost stable until the $100^{\circ} \mathrm{C}$ with only $2.63 \%$ of weight loss. This small amount of weight loss can be due to the removal of moisture from the catalyst sample. The catalyst weight loss slowly increased when the temperature exceeded $100^{\circ} \mathrm{C}$. The maximum weight loss of the catalyst about $47.58 \%$ was illustrated at $647^{\circ} \mathrm{C}$. This was in agreement with that of nonfibrous SSA catalysts reported by Ahmed et al. (2014), which was thermally stable until $100^{\circ} \mathrm{C}$ and slowly degraded when the temperature exceeded $100^{\circ} \mathrm{C}$.

In most cases, the reaction temperature for biodiesel production through esterification or transesterification is in the range of $30-65^{\circ} \mathrm{C}$. Temperature more than $65^{\circ} \mathrm{C}$ is not recommended in catalytic esterification or transesterification, because methanol starts boiling at this temperature. The SSA catalyst can be used in the transformation of fatty acid to fatty acid alkyl esters without complaint regarding thermal stability.

\section{Determination of Active Cites of Catalyst}

The active sites of the catalyst were determined by volumetric titration following the procedure available in chapter three. The active sites in mill mole per gram were calculated using Eq. 2. The result indicated that the SSA catalyst has 0.59 mill mole/gram of active cites, which was closest to that of active cites of aluminosilicate catalyst, which has the value of 0.57 mill mole/gram (Smol et al., 2015). Active sites in solid acid catalysts indicate that the concentration of proton or hydrogen ion is distributed on the surface of the catalyst. The catalyst with high Bronsted acid cites has high catalytic activity. The esterification reaction becomes faster when catalysts have high active cites. The active sites of SSA catalysts in this work indicate a good catalytic feature of the catalyst. 
Physical properties: porosity, density, and specific surface area of silica gel and SSA catalyst were determined. Porosity was correlated from pore volume and total volume using Eq. 2, and density was determined using Eq. 3. The specific surface area was determined by Blaine air permeability method using Eq. 4 . The results were available in Table 3. The detailed information was in appendix B.

Table 3. Physical properties of silica gel and silica sulfuric acid catalyst.

\begin{tabular}{|c|c|c|}
\hline Properties & Silica gel & SSA catalyst \\
\hline Porosity & 0.52 & 0.5 \\
\hline Bulk density $(\mathrm{g} / \mathrm{ml})$ & 0.546 & 0.55 \\
\hline Specific surface area $\left(\mathrm{m}^{2} / \mathrm{g}\right)$ & 352.01 & 337.42 \\
\hline
\end{tabular}

From Table 3, the density of silica gel was lower than that of the SSA catalyst, but porosity was higher than the porosity of the SSA catalyst. This indicates that, during the modification of silica gel with $\mathrm{H}_{2} \mathrm{SO}_{4}$, some pore space of silica gel was filled with a sulfonic group. The total space within particles became reduced after the modification. This was directly in agreement with that of bulk density difference. The attached sulfonic group in the SSA catalyst increased the weight of the catalyst.

The specific surface area of silica gel was $352.01 \mathrm{~m}^{2} / \mathrm{g}$ that was in the range value $350-450 \mathrm{~m}^{2} / \mathrm{g}$ of silica gel mesh (60-120) specification. However, the specific surface area of the SSA catalyst was $337.42 \mathrm{~m}^{2} / \mathrm{g}$, which was lower than that of silica gel. This indicates that some portion of porous media was filled with active species. This was in agreement with reported work, in which silica gel mesh (100-200) was modified with chlorosulfonic acid. In this experiment, specific surface areas of silica gel and SSA catalysts were $338 \mathrm{~m}^{2} / \mathrm{g}$ and $352 \mathrm{~m}^{2} / \mathrm{g}$, respectively. The catalysts with the small specific surface areas are good in biodiesel production.

\section{COMPOSITIONAL CHARACTERIZATION OF SOAPSTOCKS}

The physiochemical properties of the soapstocks were determined according to the procedures used in chapter three. The PH value of the soapstocks was measured by the PH meter. Moisture content, TFM, and NO of the soapstocks results are available in Tables 4-6. Characterized physiochemical properties of cottonseed and sunflower soap stocks are summarized in Table 7.

Table 4. Moisture content of sunflower and cottonseed soapstock.

\begin{tabular}{|c|c|c|c|c|}
\hline \multirow{2}{*}{ S/N } & \multicolumn{2}{|c|}{ Sunflower soapstock } & \multicolumn{2}{c|}{ Cottonseed soapstock } \\
\cline { 2 - 5 } & Mass of SS(g) & $\begin{array}{c}\text { Moisture content } \\
\text { (wt \%) }\end{array}$ & $\begin{array}{c}\text { Mass of } \\
\text { Soapstock(g) }\end{array}$ & $\begin{array}{c}\text { Moisture content } \\
\text { (wt \%) }\end{array}$ \\
\hline 1 & 1.98 & 34.67 & 2.07 & 33.75 \\
\hline 2 & 2.11 & 37.25 & 2.04 & 29.33 \\
\hline 3 & 2.07 & 36.32 & 2.13 & 30.47 \\
\hline Average & 2.05 & 36.08 & 2.08 & 31.18 \\
\hline
\end{tabular}


Table 5. Total fatty matter of sunflower and cottonseed soapstock.

\begin{tabular}{|c|c|c|c|c|}
\hline \multirow{2}{*}{ S/N } & \multicolumn{2}{|c|}{ Sunflower soapstock } & \multicolumn{2}{c|}{ Cottonseed soapstock } \\
\cline { 2 - 5 } & Mass of SS (g) & $\begin{array}{c}\text { Total fatty matter } \\
\text { (wt \%) }\end{array}$ & $\begin{array}{c}\text { Mass of Soapstock } \\
\text { (g) }\end{array}$ & $\begin{array}{c}\text { Total fatty matter } \\
\text { (wt \%) }\end{array}$ \\
\hline 1 & 10.18 & 39.0 & 10.23 & 46.0 \\
\hline 2 & 10.21 & 38.5 & 9.97 & 44.5 \\
\hline 3 & 10.07 & 40.0 & 10.14 & 45.5 \\
\hline Average & 10.15 & 39.2 & 10.11 & 45.3 \\
\hline
\end{tabular}

Table 6. Neutral oil of sunflower and cottonseed soapstock.

\begin{tabular}{|c|c|c|c|c|}
\hline \multirow{2}{*}{ S/N } & \multicolumn{2}{|c|}{ Sunflower soapstock } & \multicolumn{2}{c|}{ Cottonseed soapstock } \\
\cline { 2 - 5 } & Mass of SS (g) & Neutral oil (wt \%) & $\begin{array}{c}\text { Mass of } \\
\text { Soapstock (g) }\end{array}$ & Neutral oil (wt \%) \\
\hline 1 & 10.05 & 10.0 & 10.14 & 11.5 \\
\hline 2 & 10.14 & 9.5 & 10.12 & 13.0 \\
\hline 3 & 10.21 & 11.5 & 10.04 & 12.5 \\
\hline Average & 10.13 & 10.0 & 10.22 & 12.0 \\
\hline
\end{tabular}

Table 7. Physiochemical properties of cottonseed and sunflower soapstocks.

\begin{tabular}{|l|c|c|}
\hline Physiochemical properties & $\begin{array}{c}\text { Sunflower soapstock } \\
(\mathbf{w t} \%)\end{array}$ & $\begin{array}{c}\text { Cottonseed soapstock } \\
\text { (wt \%) }\end{array}$ \\
\hline PH value & 11.02 & 10.94 \\
\hline Moisture content and volatile matter & 36.10 & 31.20 \\
\hline Total fatty matter & 39.20 & 45.30 \\
\hline Neutral oil & 10.00 & 12.00 \\
\hline
\end{tabular}

$\mathrm{PH}$ value is an indicator of the soap stock's basicity. PH values of sunflower soapstock and cottonseed soap stock were 11.02 and 10.96, respectively, which are available in Table 5. These PH values were close to the literature value 10-11 reported by Ferreira et al. (2000). However, in some cases, the PH value of soapstock varies, because it depends on the quantity of caustic soda added to the crude oil. The amount of caustic soda added to the crude oil is low, and the PH value becomes low, and vice versa. In the typical reports, the PH value of sunflower soapstock is 8.6 (Marmesat et al., 2012). The high PH value indicates that soapstock is highly basic, and vice versa. In the present 
experiment, the high $\mathrm{PH}$ value in these soapstocks indicates that the soap stocks were strongly in basic media. The average percentage composition of TFM, NO, and moisture content of sunflower soapstock demonstrated some variation from the literature values (Ribeiro et al., 2014), whereas the average percentage composition of TFM and $\mathrm{NO}$ in cottonseed soap stock was in a range of the literature value 39.9-73.8 wt $\%$ and $5.6-55.7 \mathrm{wt} \%$, respectively. However, the percentage composition of moisture content and the volatile matter was as low as that from the literature value reported by the same author (Dowd, 1998). The cottonseed soapstock composition determined in the present work was closest to the literature data, whereas the compositions of sunflower soapstock demonstrated a small deviation from the literature values. This is due to the fact that the composition of soapstock varies with the nature of raw oil and the type of oil processing technology used. Both soapstocks demonstrated high TFM content in their composition. The TFM comprises NO and FFA, which are presented as soap. TFM in the soapstocks is higher than most vegetables oil seeds. A high amount of AO can be separated from the soapstock. Primarily, the use of AO is the feedstock for biodiesel production. This indicates that soapstock has an economic value.

\section{ACIDULATION RESULTS AT DIFFERENT OPERATING CONDITIONS}

The percentage conversion of soapstock to $\mathrm{AO}$ was calculated using Eq. (3.8). The results were tabulated in Table 8 .

Table 8. Percentage conversion of total fatty matter in the soapstock to acid oil.

\begin{tabular}{|c|c|c|c|c|c|c|}
\hline \multirow{2}{*}{$\begin{array}{l}\text { SS weight } \\
\quad \text { (gm.) }\end{array}$} & \multirow{2}{*}{$\begin{array}{c}\mathrm{H}_{2} \mathrm{SO}_{4}(\mathrm{wt} \\
\%)\end{array}$} & \multirow{2}{*}{$\begin{array}{l}\text { Reaction } \\
\text { time }(\mathrm{h})\end{array}$} & \multirow{2}{*}{$\begin{array}{l}\text { Temperatur } \\
\text { e }\left({ }^{\circ} \mathrm{C}\right)\end{array}$} & \multirow{2}{*}{$\begin{array}{l}\text { Mixing rate } \\
\quad(\mathrm{rpm})\end{array}$} & \multicolumn{2}{|c|}{ Conversion (\%) } \\
\hline & & & & & $\begin{array}{l}\text { Cottonseed } \\
\text { soapstock }\end{array}$ & $\begin{array}{l}\text { Sunflower } \\
\text { soapstock }\end{array}$ \\
\hline 150 & 10 & 1 & 95 & 300 & 57 & 52 \\
\hline 150 & 20 & 1 & 95 & 300 & 80 & 77 \\
\hline 150 & 30 & 1 & 95 & 300 & 74 & 75 \\
\hline
\end{tabular}

The acidulation process conditions and the results in the percentage conversion of TFM in the soapstock to AO were expressed in Table 8. In this case, the only variable parameter was the number of $\mathrm{H}_{2} \mathrm{SO}_{4}$ added to the soapstock. For $10 \%$ (wt/ wt) $\mathrm{H}_{2} \mathrm{SO}_{4}$ added to the soapstock, and the conversion is low. This indicates that the amount of $\mathrm{H}_{2} \mathrm{SO}_{4}$ added to the soap stock was insufficient to split the soap or sodium salts present in the soapstock. For 30\% (wt/wt) $\mathrm{H}_{2} \mathrm{SO}_{4}$ added, the conversion in both soap stocks was close to $20 \%$ wt of $\mathrm{H}_{2} \mathrm{SO}_{4}$ used but lower in a small amount. The excess $\mathrm{H}_{2} \mathrm{SO}_{4}$ can burn the $\mathrm{AO}$. In the present experiments, $20 \%$ by wt of $\mathrm{H}_{2} \mathrm{SO}_{4}$ was suitable for the acidulation process that gave maximum conversion in both types of soapstock. After the suitable acidulation condition was identified, the next AO separation was continuously conducted at this acidulation condition. The collection of the top phase containing $\mathrm{AO}$ was performed continuously without performing any purification process. Then, continuous purification process was performed through washing and degumming. About $770 \mathrm{~g}$ of sunflower $\mathrm{AO}$ and $860 \mathrm{~g}$ of cottonseed $\mathrm{AO}$ were obtained from the $2.5 \mathrm{~kg}$ of each sunflower and cottonseed soapstock, respectively. 


\section{PHYSIOCHEMICAL PROPERTIES OF ACID OIL}

After purifying the AO, physicochemical properties: moisture content, density, kinematic viscosity, acid value, FFA, and saponification number for each type of $\mathrm{AO}$ were determined. The standard procedures available in section three were used. The results were available in Table 9.

Table 9. Physiochemical properties of extracted acid oil.

\begin{tabular}{|l|c|c|c|c|}
\hline $\begin{array}{l}\text { Physiochemical } \\
\text { properties }\end{array}$ & Unit & Sunflower AO & Cottonseed AO & Blended AO \\
\hline Moisture content & $\mathrm{wt} \%$ & 0.45 & 0.4 & 0.43 \\
\hline Density & $\mathrm{g} / \mathrm{ml}$ & 0.91 & 0.92 & 0.915 \\
\hline Kinematic viscosity & $\mathrm{mm} / \mathrm{s}$ & 28.5 & 28.4 & 28.5 \\
\hline Acid number & $\mathrm{mgKOH} / \mathrm{g}$ & 141.8 & 151.8 & 146.8 \\
\hline FFA & $\%$ & 70.9 & 75.9 & 192 \\
\hline $\begin{array}{l}\text { Saponification } \\
\text { value }\end{array}$ & $\mathrm{mgKOH} / \mathrm{g}$ & 188.2 & 195.8 & black brown brown \\
\hline Color & & black brown & & \\
\hline
\end{tabular}

The density of the AO is in the range value of vegetable oils density $(0.91-0.93) \mathrm{g} / \mathrm{ml}$. In Table 9 , the high content of FFA in the AO indicates that the AO can be converted to FAMEs via esterification. In contrast, the presence of $\mathrm{NO}$ in the $\mathrm{AO}$ needs a transesterification reaction.

\section{BIODIESEL PRODUCTION FROM BLENDED ACID OIL}

The design expert software was used for the analysis of variance (ANOVA). The correlation between biodiesel production efficiency and process variables was evaluated using the response surface method of the CCD modeling technique. The second-order polynomial variable was fitted response (biodiesel yield) and process variables: methanol to $\mathrm{AO}$ ratio, $\mathrm{A}$, reaction time, $\mathrm{B}$, stirring rate, $\mathrm{C}$, and catalyst weight, $\mathrm{D}$. The response or the biodiesel yield was calculated using Eq. 9 and recorded in Table 10. 
Table 10. Experimental setup and responses of 5-level 4-factorial CCD design for biodiesel production from soapstock acid oil.

\begin{tabular}{|c|c|c|c|c|c|c|c|}
\hline \multirow{2}{*}{ Run } & \multirow{2}{*}{$\begin{array}{l}\mathrm{MeOH} \text { to } \\
\mathrm{AO} \text { molar } \\
\quad \text { ratio }\end{array}$} & \multirow{2}{*}{$\begin{array}{l}\text { Time } \\
\text { (hr.) }\end{array}$} & \multirow{2}{*}{$\begin{array}{l}\text { Mixing } \\
\text { rate(rpm) }\end{array}$} & \multirow{2}{*}{$\begin{array}{c}\text { Catalyst } \\
(\text { wt \%) }\end{array}$} & \multicolumn{2}{|c|}{ Yield (\%) } & \multirow{2}{*}{ Residual } \\
\hline & & & & & Actual & Predicted & \\
\hline 1 & 7 & 3 & 350 & 5.5 & 89.18 & 88.75 & 0.43 \\
\hline 2 & 7 & 1 & 350 & 5.5 & 53.56 & 53.09 & 0.48 \\
\hline 3 & 10 & 4 & 500 & 3 & 59.05 & 57.16 & 1.89 \\
\hline 4 & 10 & 2 & 500 & 3 & 62.15 & 64.25 & -2.10 \\
\hline 5 & 4 & 4 & 500 & 3 & 69.90 & 72.80 & -2.90 \\
\hline 6 & 10 & 2 & 200 & 8 & 83.34 & 82.27 & 1.07 \\
\hline 7 & 7 & 3 & 350 & 5.5 & 88.58 & 88.75 & -0.17 \\
\hline 8 & 13 & 3 & 350 & 5.5 & 70.31 & 70.96 & -0.65 \\
\hline 9 & 4 & 4 & 500 & 8 & 89.06 & 86.95 & 2.11 \\
\hline 10 & 7 & 3 & 350 & 5.5 & 88.05 & 88.75 & -0.70 \\
\hline 11 & 7 & 3 & 350 & 0.5 & 70.09 & 70.72 & -0.63 \\
\hline 12 & 7 & 3 & 350 & 5.5 & 90.68 & 88.75 & 1.93 \\
\hline 13 & 4 & 2 & 500 & 8 & 54.44 & 56.73 & -2.29 \\
\hline 14 & 7 & 3 & 350 & 5.5 & 85.65 & 88.75 & -3.10 \\
\hline 15 & 10 & 2 & 500 & 8 & 66.88 & 66.71 & 0.17 \\
\hline 16 & 4 & 4 & 200 & 8 & 76.31 & 76.04 & 0.27 \\
\hline 17 & 10 & 4 & 200 & 8 & 84.22 & 83.60 & 0.62 \\
\hline 18 & 4 & 2 & 500 & 3 & 61.12 & 58.59 & 2.53 \\
\hline 19 & 10 & 4 & 500 & 8 & 75.11 & 75.62 & -0.51 \\
\hline 20 & 4 & 2 & 200 & 3 & 52.75 & 54.07 & -1.32 \\
\hline 21 & 7 & 3 & 50 & 5.5 & 67.24 & 69.77 & -2.53 \\
\hline 22 & 7 & 3 & 350 & 5.5 & 90.36 & 88.75 & 1.61 \\
\hline 23 & 7 & 3 & 350 & 10.5 & 87.82 & 88.52 & -0.70 \\
\hline 24 & 1 & 3 & 350 & 5.5 & 57.06 & 57.73 & -0.67 \\
\hline 25 & 7 & 5 & 350 & 5.5 & 66.83 & 68.63 & -1.80 \\
\hline 26 & 4 & 4 & 200 & 3 & 63.67 & 60.69 & 2.98 \\
\hline 27 & 10 & 4 & 200 & 3 & 64.41 & 63.95 & 0.46 \\
\hline 28 & 10 & 2 & 200 & 3 & 79.66 & 78.62 & 1.04 \\
\hline 29 & 4 & 2 & 200 & 8 & 54.67 & 53.4 & 1.27 \\
\hline 30 & 7 & 3 & 650 & 5.5 & 67.52 & 66.31 & 1.21 \\
\hline
\end{tabular}


Table 11. Fit summary of the suggested quadratic model.

\begin{tabular}{|l|l|l|l|}
\hline Standard deviation & 2.27 & R-square & 0.9837 \\
\hline Mean & 72.32 & Adjusted R-square & 0.9685 \\
\hline Coefficient of variation \% & 3.14 & Predicted R-square & 0.9212 \\
\hline Lack of fit P-value & 0.2613 & Adequacy precision & 22.1757 \\
\hline & & Sequential P-value & $<0.0001$ \\
\hline
\end{tabular}

Table 12. The ANOVA results of the quadratic model for the correlations of response (biodiesel yield) and process variables.

\begin{tabular}{|l|c|c|c|c|c|c|}
\hline Source & $\begin{array}{c}\text { Sum of } \\
\text { Squares }\end{array}$ & Df & $\begin{array}{c}\text { Mean } \\
\text { Square }\end{array}$ & F-value & p-value & \\
\hline Model & 4684.62 & 14 & 334.62 & 64.68 & $<0.0001$ & Significant \\
\hline $\begin{array}{l}\text { A-MeOH to AO } \\
\text { molar ratio }\end{array}$ & 262.68 & 1 & 262.68 & 50.78 & $<0.0001$ & \\
\hline B-Reaction time & 362.39 & 1 & 362.39 & 70.05 & $<0.0001$ & \\
\hline C-Stirring rate & 17.96 & 1 & 17.96 & 3.47 & 0.0821 & \\
\hline D-Catalyst & 475.08 & 1 & 475.08 & 91.83 & $<0.0001$ & \\
\hline AB & 453.69 & 1 & 453.69 & 87.7 & $<0.0001$ & \\
\hline AC & 356.83 & 1 & 356.83 & 68.98 & $<0.0001$ & \\
\hline AD & 18.58 & 1 & 18.58 & 3.59 & 0.0775 & \\
\hline BC & 57.53 & 1 & 57.53 & 11.12 & 0.0045 & \\
\hline BD & 256.16 & 1 & 256.16 & 49.52 & $<0.0001$ & \\
\hline CD & 1.43 & 1 & 1.43 & 0.276 & 0.607 & \\
\hline$A^{2}$ & 1020.9 & 1 & 1020.9 & 197.34 & $<0.0001$ & \\
\hline$B^{2}$ & 1333.78 & 1 & 1333.78 & 257.82 & $<0.0001$ & \\
\hline$C^{2}$ & 735.15 & 1 & 735.15 & 142.11 & $<0.0001$ & \\
\hline$D^{2}$ & 143 & 1 & 143 & 27.64 & $<0.0001$ & \\
\hline Residual & 77.6 & 15 & 5.17 & & & \\
\hline Lack of Fit & 60.97 & 10 & 6.1 & 1.83 & 0.2613 & not significant \\
\hline Pure Error & 5 & 3.33 & & & \\
\hline Cor Total & 16.63 & 29 & & & & \\
\hline
\end{tabular}


The adequacy of the model was evaluated by P-value, F-value, lack of fit, and coefficients of determination. The F-value of 64.68 indicates that the quadratic model was significant. The adequacy and significance of the established model were further supported by the high value of the coefficient of determination terms: $\mathrm{R}^{2}$ value of 0.9837 and adjusted $R^{2}$ value of 0.9594 . This implies that the established quadratic model explained $98.37 \%$ of the variation in the experimental results, further meaning that the actual values from the experimental result were closer to those of the predicted values. The very small difference (less than 0.2 ) of adjusted $\mathrm{R}^{2}$ of 0.9685 and predicted $\mathrm{R}^{2}$ of 0.9212 supported the adequacy of the model. In addition, the signal to noise ratio of 22.176 indicates an adequate signal. Furthermore, the adequacy of the model for experimental data was measured by the lack of fit. From the ANOVA result, the lack of fit P-value of 0.2613 and F-value of 1.83 indicates that the lack of fit is not significant. Therefore, a nonsignificant lack of fit is good. Moreover, from the ANOVA analysis, the lower value of the coefficient of variation $(\mathrm{C} . \mathrm{V} .=3.14 \%)$ indicates the better precession and reliability of the experiments were carried out. The C.V. as a ratio of the standard error of the estimate to the mean value of the observed response (as $\%$ biodiesel yield) is the measure of reproducibility of the model, and as a general rule, a model can be considered reasonably reproducible. The coefficient terms with P-value greater than 0.05 are not significant, whereas P-values less than 0.0500 indicate that the model terms are significant. The ANOVA results in Table 12 showed that the linear terms $\mathrm{A}, \mathrm{B}, \mathrm{D}$, interaction terms $\mathrm{AB}, \mathrm{AC}, \mathrm{BC}$, and $\mathrm{BD}$, and quadratic terms $\mathrm{A}^{2}, \mathrm{~B}^{2}, \mathrm{C}^{2}$, and $\mathrm{D}^{2}$ were significant.

\section{FINAL EQUATION IN TERMS OF CODED FACTORS}

The response change at a given range of process variables can be predicted using the coded equation. The intercept of codded factors is in the center of the design space. The equation in terms of coded factors is important to determine the relative influence of process variables by comparing the coefficients of the variables. The final equation of the regression model in terms of coded factors was represented by Equation 1. The analysis of design expert software is based on a coded equation.

$$
\begin{aligned}
\mathrm{BY}(\%) & =88.75+3.31 \mathrm{~A}+3.89 \mathrm{~B}-0.865 \mathrm{C}+4.45 \mathrm{D} \\
& -5.33 \mathrm{AB}-5.72 \mathrm{AC}+1.08 \mathrm{AD}+1.9 \mathrm{BC}+4 \mathrm{BD} \\
& -0.2987 \mathrm{CD}-6.1 \mathrm{~A}^{2}-6.97 \mathrm{~B}^{2}-5.18 \mathrm{C}^{2}-2.28 \mathrm{D}^{2}
\end{aligned}
$$

Where; BY - Biodiesel Yield, A - Methanol to acid oil molar ratio, B - Reaction time, C-Stirring rate, D - Catalyst weight

The optimum experimental value of biodiesel yield (90.68\%) and the predicted value (88.75\%) were presented with a very small deviation of $0.021 \%$ between experimental and predicted biodiesel yield. This indicates that the model Eq. 19 is suitable and sufficient to predict the biodiesel yield using SSA catalyst under given range values of process variables. 


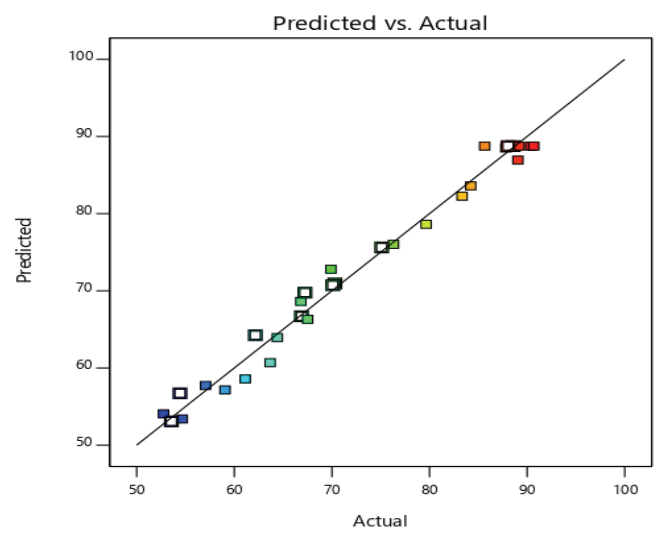

(a)

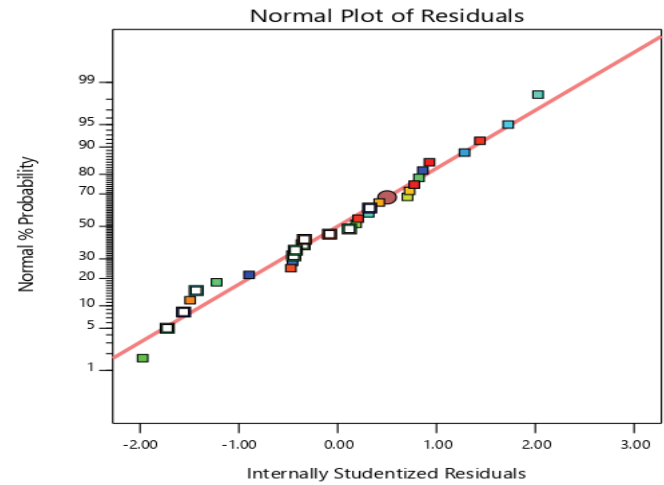

(b)

Figure 5. (a) Actual versus predicted biodiesel yield values. (b) Normal plots of residuals.

Figure 5(a) represents that the actual verse predicted biodiesel yield and indicated that the actual values were fitted on the linear straight line. This linear line drowns at $45^{\circ}$ indicating that the predicted and actual biodiesel yields were closer to each other. It was further supported by a high correlation coefficient value $\left(\mathrm{R}^{2}=0.9837\right)$, which was closer to the unity. This implies that experimental data were in reasonable agreement with $\mathrm{R}^{2}$ value, which means that data agrees well with a model to predict biodiesel yield at given range values of process variables.

Residual is the difference between actual and predicted value. Internal standardized residual is vital to check the goodness of data fit on the regression line under an established model. In Figure 5 (b), all the residuals were fitted on a linear line, which indicates the normal distribution of residuals of each point on linear regression line. In the above plot, there is not any abnormality observed regarding the distribution of residuals. This implies that data was well fitted, and it is possible to predict the response under given ranges of process variables.

\section{INTERACTION EFFECT OF PROCESS VARIABLES ON THE BIODIESEL YIELD}

\section{Interaction Effect of Stirring Rate, Reaction Time, and Methanol to Acid Oil Ratio}

The interaction effect of methanol to $\mathrm{AO}$ ratio and reaction time was represented by a 3D surface plot in Figure 6(a). The literature reported on the effect of these factors stated in the literature section. Works of literature say that high alcohol to oil molar ratio can facilitate biodiesel production, whereas low alcohol to oil ratio requires a long time for the completion of the reaction and even results in low yield. In the present experiment, at a constant stirring rate of 350rpm and a catalyst of $5.5 \mathrm{wt} \%$, the interaction effect of the reaction time and methanol to the AO molar ratio was observed. The lowest value of methanol to oil ratio provided $57.06 \%$ of biodiesel yield, and the highest value provided $70.31 \%$ of biodiesel yield. The results demonstrated that an increase in methanol to the AO molar ratio resulted in an increase in the biodiesel yield. This further increase from its center point resulted in a slight reduction of biodiesel yield since FFA and NO under acid catalysis require long reaction time. By keeping other factors at the center point, the lowest range value of reaction time (i.e., $1 \mathrm{hr}$ ) provided $53.56 \%$ of biodiesel yield. The increase in reaction time until $3 \mathrm{hr}$ resulted in higher biodiesel yield. This further increase in the reaction time (5hr) resulted in a slight reduction of biodiesel yield (66.83\%). 
Long reaction time and higher alcohol to $\mathrm{AO}$ ratio can reverse the equilibrium towards the reactant side. The independent factors, reaction time and methanol to AO molar ratio, demonstrated a significant effect on biodiesel yield. This was supported by ANOVA P-value $(<0.0001)$ for both process variables. The interaction effect of both variables resulted in an increase of biodiesel yield until the center point, and further increase resulted in a reduction of the biodiesel yield. The maximum biodiesel yield (90.68\%) is obtained at a reaction time of $3 \mathrm{hrs}$ and methanol to the AO molar ratio of 7:1. The significant effect of the interaction of these two variables was also supported by ANOVA P-value $(<0.0001)$.

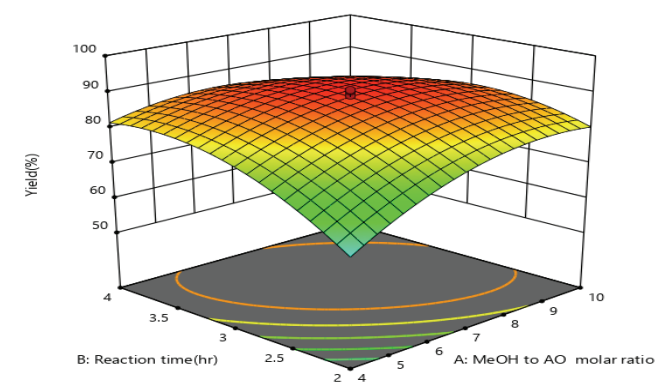

(a)

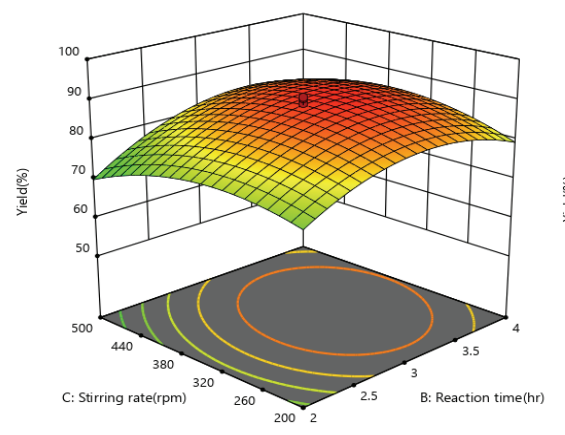

(c)

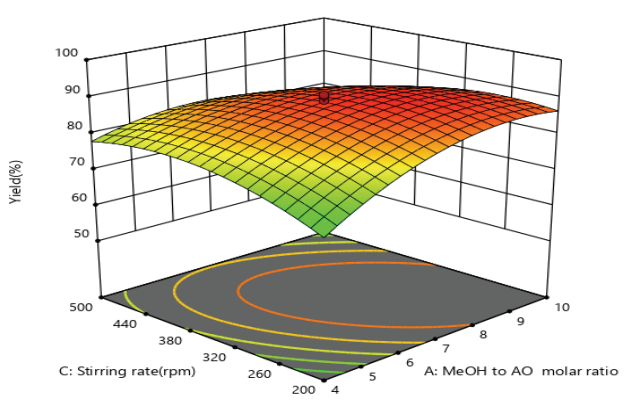

(b)

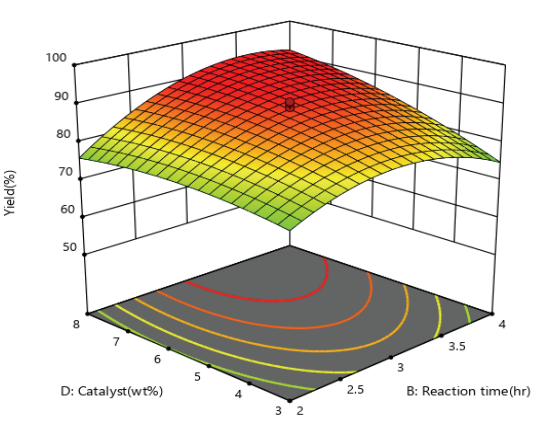

(d)

Figure 6. 3D surface plot of the interaction effect of (a) methanol to acid oil molar ratio and reaction time on the biodiesel yield: (b) stirring rate and methanol to acid oil ratio on the biodiesel yield, (c) stirring rate and reaction time on the biodiesel yield, and (d) catalyst weight and reaction time on the biodiesel yield.

The interaction effect of the stirring rate and molar ratio of methanol to $\mathrm{AO}$ was represented in a $3 \mathrm{D}$ surface plot in Figure 6(b). The increase in a molar ratio of methanol to AO resulted in an increase in biodiesel yield, whereas the independently stirring rate has no significant effect on the biodiesel yield. At constant center points of other factors, the lowest stirring rate $(50 \mathrm{rpm})$ provided $67.24 \%$ of biodiesel yield, and the highest stirring rate $(650 \mathrm{rpm})$ provided $67.52 \%$ of biodiesel yield. The P-value of the stirring rate was 0.0821 , which indicates that the independent factor (stirring rate) has no significant effect on biodiesel yield. However, the interactions of both process variables have a significant effect on biodiesel production that was supported by P-value of 0.0001 . The maximum biodiesel yield $(90.68 \%)$ is obtained at methanol to $\mathrm{AO}$ molar ratio of 7:1 and stirring rate of 350rpm at a constant reaction time of $3 \mathrm{hr}$ and catalyst weight of $5.5 \mathrm{wt} \%$. 


\section{Interaction Effect of Reaction Time, Catalyst Weight, and Stirring Rate}

The interaction effect of stirring rate and reaction time was shown in the $3 \mathrm{D}$ surface plot in Figure 6(c). The interactions of reaction time and stirring rate have a significant effect on biodiesel yield. As discussed above, the reaction time of $3 \mathrm{hr}$ resulted in higher biodiesel yield, while the stirring rate has a low effect on biodiesel production. The interaction of two factors demonstrated high biodiesel yield (90.68) at the center point. The higher stirring rate for long reaction time can reverse reaction back to the reactant side. This reduced the yield of biodiesel at the upper limit of these factors

The interaction effect of catalyst weight and reaction time on biodiesel yield was shown in the 3D plot in Figure 6(d). The increase in catalyst weight resulted in an increase in biodiesel yield. Catalyst weight beyond 5.5\% demonstrated almost constant feature on biodiesel yield. In contrast, reaction time beyond center point resulted in a decrease in biodiesel production efficiency. The interaction of two factors demonstrated a significant effect on biodiesel yield. The maximum biodiesel yield (90.68\%) was obtained at the center point of all four factors.

\section{NUMERICAL OPTIMIZATION}

The targeted objective of the present study was to maximize the yield of biodiesel produced from the blended AO using the SSA catalyst. The optimum conditions of the four factors, methanol to AO molar ratio, reaction time, stirring rate, and catalyst weight, were determined by using a numerical optimization feature of design expert software. The software manipulated the combinations of the factors that satisfy the requirements for response and each of the factors. All the factors and responses with their constraint of optimization criteria were available in Table 13 .

Table 13 involved the ultimate goal of response, upper and lower limits of the factors (methanol to AO molar ratio, stirring rate, reaction time, and catalyst weight), and response (\% of biodiesel yield). The ultimate goal of response was maximizing the biodiesel yield within the given range values of process variables. The optimum conditions obtained were then evaluated by the composite desirability, which has a value from 0 to 1 . The highest composite desirability of 1.0 at an optimized process condition was obtained from design expert software. It indicates that the degree of satisfaction of the optimum conditions for the ultimate goal of response was successfully attained.

Table 13. Ultimate goal of response and constraints of process variables for optimization.

\begin{tabular}{|l|c|c|c|c|}
\hline \multicolumn{1}{|c|}{ Process variables } & Unit & Ultimate goal & $\begin{array}{c}\text { Lower limit } \\
\text { value }\end{array}$ & Upper limit value \\
\hline Methanol to acid oil ratio & mole/mole & in range & 4 & 10 \\
\hline Reaction time & $\mathrm{hr}$ & in range & 2 & 4 \\
\hline Mixing rate & $\mathrm{rpm}$ & in range & 200 & 500 \\
\hline Catalyst weight & $\mathrm{wt} \%$ & in range & 3 & 8 \\
\hline FAMEs & $\%$ & maximize & 52.75 & 90.68 \\
\hline
\end{tabular}


Table 14. Optimum conditions and model validation.

\begin{tabular}{|l|c|c|}
\hline Process variables & Unit & Optimum results \\
\hline Methanol to acid oil ratio & mole/mole & 7.69 \\
\hline Reaction time & $\mathrm{hr}$. & 3.58 \\
\hline Mixing rate & $\mathrm{rpm}$ & 292.34 \\
\hline Catalyst weight & $\mathrm{wt} \%$ & 7.87 \\
\hline FAMEs from software & $\%$ & 92.66 \\
\hline Desirability & -- & 1 \\
\hline FAMEs from experiment & $\%$ & 92.62 \\
\hline Deviation & $\%$ & 0.043 \\
\hline
\end{tabular}

The triplicate experiments were conducted to attain the optimum conditions given by design expert software. The average value of triplicates of biodiesel yield was $92.62 \%$, while the software biodiesel yield was $92.66 \%$ as shown in Table 14 . There was a very small deviation $(0.043 \%)$ between software and experimental result at an optimum condition, which indicates that the model agrees well with experimental data. The maximum FFA conversion is achieved using methanol to AO molar ratio of 9:1 and above for reaction time from 2 to $6 \mathrm{hr}$. Most literature reported more than $94 \%$ of FFA conversion to fatty acid esters, which was achieved at a temperature of $60^{\circ} \mathrm{C}$ and above. In the present study, the maximum biodiesel yield of $(92.62 \%)$ was obtained from experimentation at optimized conditions. In addition, both NO and FFA were simultaneously converted to FAMEs. The optimized biodiesel was characterized.

\section{PHYSIOCHEMICAL PROPERTIES OF BIODIESEL}

Table 15. Comparison of physicochemical properties of produced biodiesel with ASTM/EN standards.

\begin{tabular}{|c|l|c|c|c|c|}
\hline \multirow{2}{*}{$\mathrm{S} / \mathrm{N}$} & \multicolumn{1}{|}{ Properties } & Unit & \multirow{2}{*}{ FAMEs } & \multicolumn{2}{|c|}{ FAME standards } \\
\cline { 5 - 6 } & & & & ASTM D6751 & EN 14214 \\
\hline 1 & Moisture content & $\%(\mathrm{v} / \mathrm{v})$ & 0.04 & $\leq 0.05$ & -- \\
\hline 2 & Specific gravity & -- & 0.89 & $1.9-6$ & $0.86-0.9$ \\
\hline 3 & $\begin{array}{l}\text { Kinematic } \\
\text { viscosity }\end{array}$ & $\mathrm{mm}^{2} / \mathrm{s}$ & 0.47 & $\leq 0.05$ & $\leq 0.5$ \\
\hline 4 & Acid value & $(\mathrm{mgKOH} / \mathrm{g})$ & 1.2 & & -- \\
\hline 5 & FFA & $\%$ & 0.6 & & \\
\hline
\end{tabular}




\begin{tabular}{|c|l|c|c|c|c|}
\hline 6 & $\begin{array}{l}\text { Saponification } \\
\text { value }\end{array}$ & $(\mathrm{mg} \mathrm{KOH} / \mathrm{g})$ & 167.5 & -- & -- \\
\hline 7 & Iodine value & $\mathrm{mgI}_{2} / 100 \mathrm{~g}$ & 124 & -- & $\leq 120$ \\
\hline 8 & Color & ---- & Light brown & -- & -- \\
\hline 9 & HHV & $\mathrm{MJ} / \mathrm{Kg}$ & 40.7 & -- & -- \\
\hline 10 & LHV & $\mathrm{MJ} / \mathrm{Kg}$ & 36.3 & & $\leq 0.02$ \\
\hline 11 & Ash content & $\%(\mathrm{~m} / \mathrm{m})$ & 0.02 & $\geq 47$ & $\geq 51$ \\
\hline 12 & Cetane number & --- & 51 & $\geq 93$ & $\geq 120$ \\
\hline 13 & Flash point & ${ }^{\circ} \mathrm{C}$ & 176 & $\geq 92$ \\
\hline
\end{tabular}

Specific gravity/density is an important parameter used to determine the homogeneity of the biodiesel. This shows the airless combustion of fuel. The atomization of the fuel can be influenced by its density. The limit of the density of the biodiesel was not specified in ASTM D6751 standards. In EN 14214 specifications, the density of standard biodiesel can be in the range of $0.86-0.9 \mathrm{~g} / \mathrm{ml}$. In this experiment, biodiesel density was $0.89 \mathrm{~g} / \mathrm{ml}$, which was in the range of EN 14214 specifications. From Table 15, the fuel density falls under EN 14214 specification range and indicates the good ignition property of the fuel.

The moisture content in fuel can express the fuel property. The higher moisture content can affect the combustion of the fuel. In the ASTM D6751 standard, the maximum moisture content of standard biodiesel is $0.05(\mathrm{v} / \mathrm{v}) \%$. In the present experiment, the moisture content of the biodiesel is $0.04(\mathrm{v} / \mathrm{v}) \%$, which is in a limit of ASTM D6751. The lower moisture content of biodiesel indicates good fuel quality, meaning that fuel can easily be combustible.

The fuel quality can be determined by its viscosity. Fuel with lower viscosity can easily atomize and lubricate. However, fuel with very low viscosity results in an increase in wear and poor combustion, whereas fuel with very high viscosity results in the formation of a large number of droplets and an increase in exhaust emission. In the ASTM D6751-03 standard, the kinematic viscosity of standard biodiesel is under the range of $1.9-6 \mathrm{~mm}^{2} / \mathrm{s}$. In the present experiment, the kinematic viscosity of produced biodiesel was $4.7 \mathrm{~mm}^{2} / \mathrm{s}$. This was under the range of ASTM D6751 biodiesel standard.

The acid value of FFA content in biodiesel is an important parameter to decide the quality of biodiesel. The presence of high acid value in biodiesel or diesel blends indicates that the fuel can oxidize easily, which leads to composition change, thereby reducing fuel quality. In EN 14214 standard, the maximum acid value of standard diesel fuel or biodiesel is $0.5 \mathrm{mgKOH} / \mathrm{g}$. In the present study, the acid value of biodiesel was $1.2 \mathrm{mgKOH} / \mathrm{g}$. This acid value was closest to European biodiesel specification (i.e., EN 14214 standard) and American biodiesel specification, ASTM D6751. The complete conversion of all FFA in the AO to fatty acid esters is difficult.

The higher heating value (HHV) of fuel is an important parameter to determine the calorific value of the fuel. HHV was determined according to Eq. (3.14). The calculated HHV of produced biodiesel was $40.7 \mathrm{MJ} / \mathrm{Kg}$. In European biodiesel standard (EN 14213) as heating oil, the minimum net calorific value is $35 \mathrm{MJ} / \mathrm{kg}$. The gross 
calorific value of biodiesel is not specified in ASTM D6751 as well as EN 14214 standards. It is better if fuel has a high gross calorific value. The HHV of the present biodiesel indicates that the biodiesel has good gross calorific value. The LHV of produced biodiesel was $36.3 \mathrm{MJ} / \mathrm{Kg}$, which was smaller than gross calorific value. This implies that, during combustion, high amount of heat can be recovered by the secondary condenser.

Iodine value is also called the iodine index. The degree of unsaturation can be determined by iodine value. It is important to determine the quality of biodiesel. Fuel with high iodine value has more $\mathrm{C}=\mathrm{C}$ bonds present in the fuel. The lower the iodine value, the less $\mathrm{C}=\mathrm{C}$ bonds present in the fuel. Diesel fuel with very high iodine value cannot properly ignite in the engines. This is because the degree of unsaturation increases; the volatility of the fuel decreases, which results in poor combustion. In European biodiesel standard, EN 14214 standards, the maximum iodine value of the standard B100 biodiesel is $120 \mathrm{gI} / 00 \mathrm{~g}$. In the present study, the iodine value of produced biodiesel is $124 \mathrm{gI} / 100 \mathrm{~g}$, which was closest to that of EN 14214 standard biodiesel specification.

Cetane number is an important parameter to determine the ignition quality of diesel fuel as well as biodiesel. Cetane value fuel is lower than that of biodiesel. This implies that biodiesel is more volatile than diesel fuel. In the ASTM D6751 standard, the minimum cetane value of B100 biodiesel is 47, whereas, in European biodiesel standard (EN 14214) specification, the minimum cetane value for standard biodiesel is 51.

In the present experiment, biodiesel produced from soapstock has a cetane number of 51, which was obtained using Eq. 17. This cetane value full field the limits specified in ASTM D6751 and EN 14214 standards. The cetane value of biodiesel below 39 is not recommended, because biodiesel with very low cetane value will result in exhaust emission and difficulty of fuel combustion in the engine. The high cetane value indicates short ignition time delay, which shows that the engine can operate at low temperatures. However, very high cetane value leads to incomplete combustion. In addition, fuel with very high cetane value can generate NOx emission. Literature suggested cetane value of biodiesel should be between 39 and 65, which indicates good ignition quality of biodiesel.

\section{FTIR CHARACTERIZATION OF BIODIESEL}

The FTIR spectra of biodiesel produced from blended AO of sunflower and cottonseed soapstock are represented in Figure 7.

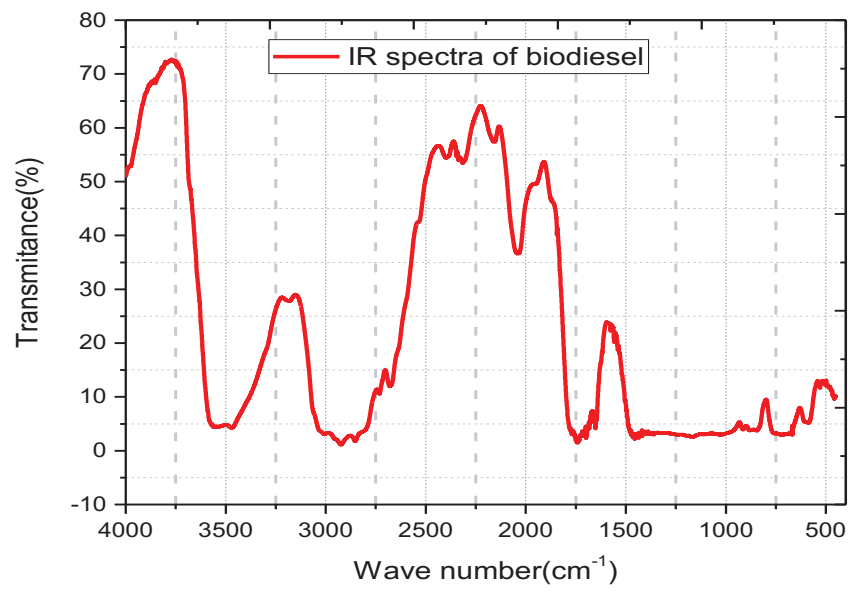

Figure 7. FTIR spectra of produced biodiesel. 
The available functional groups of biodiesel were determined from the FTIR spectroscopic analysis. The major absorption peaks of figure 7 were interpreted based on the standard method and literature (Grace, 2013). The major IR bands and entire bonds or functional groups were available in Table 16. The major absorption bands of produced biodiesel in the present experiment were $3006.83 \mathrm{~cm}^{-1}, 2924.53 \mathrm{~cm}^{-1}, 2852.22 \mathrm{~cm}^{-1}, 2036 \mathrm{~cm}^{-1}, 1740 \mathrm{~cm}^{-1}, 1651 \mathrm{~cm}^{-1}$, $1455.54 \mathrm{~cm}^{-1}, 1631 \mathrm{~cm}^{-1}, 680-760 \mathrm{~cm}^{-1}$, and $590.78 \mathrm{~cm}^{-1}$. The produced biodiesel in the present experiment showed similar absorption peaks with the biodiesel produced from peanut oil (Oyerinde and Bello, 2016). And also the same IR spectrum result of biodiesel produced from sunflower, soya bean, and palm oil was reported (Donnell et al., 2013). All in all, the present biodiesel is similar to the biodiesel produced from different feedstocks, because it was proven by IR spectra that demonstrated similar absorption bands.

Table 16. Major bands and functional groups of IR spectra of produced biodiesel.

\begin{tabular}{|l|l|l|}
\hline Wavenumber $\left(\mathrm{cm}^{-1}\right)$ & Types of vibration & Available bond/functional groups \\
\hline $3150-3633$ & Stretching/weak vibration & O-H (alcohol) \\
\hline 3006.83 & Asymmetric stretching & C-H (alkenes) \\
\hline 2924.53 & Asymmetric stretching & C-H(alkanes) \\
\hline 2852.22 & Symmetric stretching & C-H(methylene) \\
\hline $2310 \$ 2400$ & Stretching & C-H(alkanes) \\
\hline 2036 & Stretching & C-H(alkanes) \\
\hline 1740 & Stretching/weak vibration & C=O(carbonyl group) \\
\hline 1651 & Bending & $-\mathrm{C}=\mathrm{C}($ carbon-carbon double bond) \\
\hline 1455.54 & Stretching & C-C (carbon-carbon bond) \\
\hline 1631 & Stretching/weak vibration & C-O(alkoxy group) \\
\hline $680-760$ & Bending & $=\mathrm{C}-\mathrm{H}($ alkene group) \\
\hline 590.78 & Stretching & (CH)n (alkane group) \\
\hline
\end{tabular}

\section{CATALYST REUSABILITY TEST}

In order to verify catalyst stability, the used SSA catalyst was washed with acetone and dried in an oven at $60 \mathrm{oC}$ for $1 \mathrm{hr}$ to remove any tars and adsorbed impurities from the catalyst as reported by Ramana et al. (2014). This process was performed after each cycle run. Three cycle runs were conducted on biodiesel production from blended $\mathrm{AO}$ at optimum process conditions. The yield of FAMEs for two consecutive runs demonstrated that there was no apparent reduction in FAMEs yield. The decline of FAMEs yield was observed at the third run that was shown in figure 8 . This can be due to active cites leaching to the reaction media and blockage of the active sites by adsorbent materials. A similar result was reported on the esterification of AO to FAMEs. In this experiment, SSA catalyst was 
reused for two runs without significant yield reduction in five consecutive runs. The catalytic activity loss was observed after the second run due to blockage of active cites (Shah et al., 2014). Almost the same view was reported on SSA catalyst reusability, which was stable for three consecutive runs (Ghosh et al., 2014).

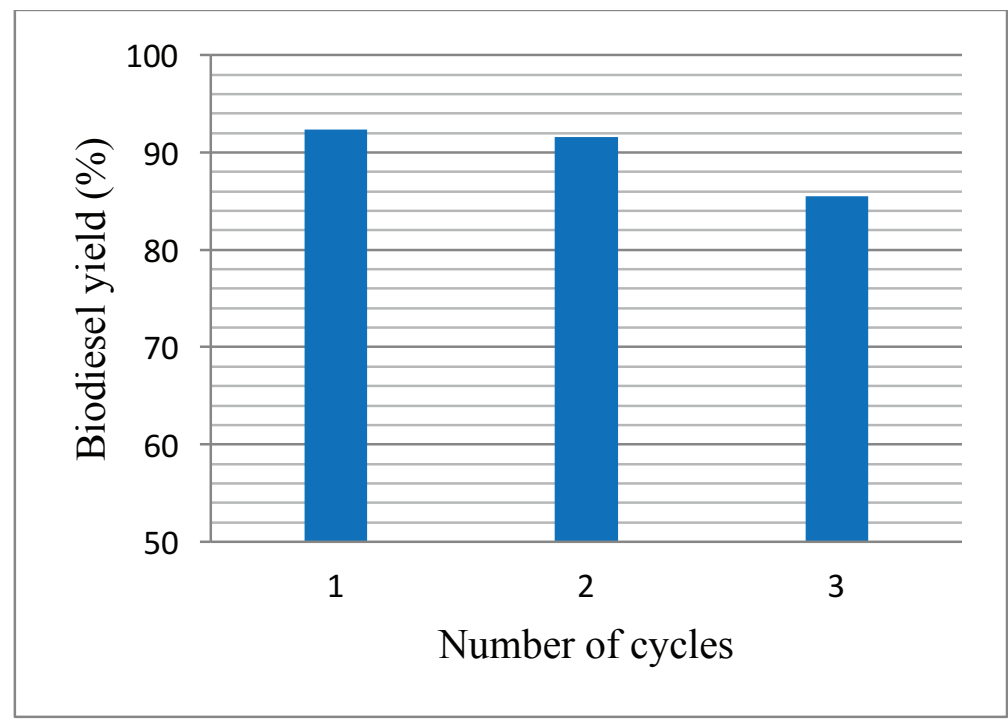

Figure 8. Repeated use of SSA catalyst for biodiesel production from soapstock acid oil at optimum process condition.

\section{CONCLUSION}

The production, optimization, and characterization of biodiesel from equal weight ratio blended AO obtained from sunflower and cottonseed soapstock using SSA catalyst were carried out. First, silica sulfuric acid catalyst was prepared by sulfonation of silica gel (60-120mesh) with $\mathrm{H}_{2} \mathrm{SO}_{4}$, and its thermal stability, functional groups, acid cites, physical properties, and noncrystalline structure were characterized. The characterized result showed that the prepared SSA catalyst exhibited good catalytic performance. Optimization was carried out using RSM of design expert software with four important parameters (methanol to oil molar ratio, catalyst weight, stirring rate, and reaction time) to maximize biodiesel yield. The ANOVA results indicated that satisfactory results were achieved, which were supported by a statistically significant quadratic model with nonsignificant lack of fit and coefficient of determination, $\mathrm{R}^{2}$ of $98.37 \%$ and adjusted $\mathrm{R}^{2}$ of $96.5 \%$ under the given range values of process parameters. From the experimental results, the maximum biodiesel yield of $90.68 \%$ was obtained using methanol to AO molar ratio of 7:1 using catalyst $5.5(\% \mathrm{wt} / \mathrm{wt})$ with a stirring rate of $300 \mathrm{rpm}$ at $3 \mathrm{hr}$ reaction time. The maximum biodiesel yield from the experimentation at optimized condition was $92.62 \%$. The important fuel properties of produced biodiesel were tested. The heating values, acid value, iodine value, moisture content, viscosity, flash point, cetane number, density, and ash content of the biodiesel conformed to the ASTM and EN standard values. In addition, FTIR characterization of produced biodiesel conformed that of standard biodiesel IR spectra. Three cycles for SSA catalyst reusability experiments were performed at optimum conditions. The catalyst was stable for two consecutive runs without apparent biodiesel yield reduction. In general, simultaneous esterification and transesterification of soapstock AO using SSA catalyst are attractive in biodiesel production. 


\section{REFERENCES}

Ahmad, M. and Khan, M. A. 2007. Biodiesel from Non Edible Oil Seeds : a Renewable Source of Bioenergy, 2005.

Aldana, P.U., Ocampo, F., Kobl, K., Louis, B, Thibault-Starzyk, F., Daturi, M., Bazin, P., Thomas, S. and Roger, A.C. 2013. Catalytic CO2 valorization into $\mathrm{CH} 4$ on Ni-based ceria-zirconia. Reaction mechanism by operando IR spectroscopy. Catalysis Today, 215, pp.201-207.

Amoozadeh, A. and Rahmani, S. 2015. Nano-WO3-supported sulfonic acid: New, efficient and high reusable heterogeneous nano catalyst. Journal of Molecular Catalysis A: Chemical, 396, pp.96-107.

Ashraful, A.M., Masjuki, H.H., Kalam, M.A., Fattah, I.R., Imtenan, S., Shahir, S.A. and Mobarak,H.M.2014. Production and comparison of fuel properties, engine performance, and emission characteristics of biodiesel from various non-edible vegetable oils: A review. Energy Conversion and Management, 80, pp.202-228.

Balachandran, C., Muñoz, J.F. and Arnold, T. 2017. Characterization of alkali silica reaction gels using Raman spectroscopy. Cement and Concrete Research, 92, pp.66-74.

Bilgen S.2014. Structure and environmental impact of global energy consumption. Renewable and Sustainable Energy Reviews, 38, pp.890-902.

Deng, X., Fang, Z. and Liu, Y.H. 2010. Ultrasonic transesterification of Jatropha curcas L. oil to biodiesel by a two-step process. Energy Conversion and Management, 51(12), pp.2802-2807.

Donnell, S. O,Larvo A. 2013. A Review on the Spectroscopic Analyses of Biodiesel, 2(7), pp. 137-146.

Dowd M. K. 1998. Gas chromatographic Characterization of Soapstocks from Vegetable Oil Refining, 816, pp. $185-193$.

Ferreira, L., Vidal, M.M. and Gil, M.H. 2011. Evaluation of poly (2-hydroxyethyl methacrylate) gels as drug delivery systems at different pH values. International journal of pharmaceutics, 194(2), pp.169-180.

Ghosh, S., Acharyya, S.S., Adak, S., Konathala, L.S., Sasaki, T. and Bal, R.2014. Selective oxidation of cyclohexene to adipic acid over silver supported tungsten oxide nanostructured catalysts. Green Chemistry, 16(5), pp.2826-2834.

Grace J. J. 2013. Fourier Transform Infrared Spectrophotometric Analysis of Functional Groups in Biodiesel Produced from Oils of Ricinus Communis , Hevea Brasiliensis and Jatropha Curcas Seeds, 2(6), pp. 11161121.

Hanjra, M.A. and Qureshi, M.E.2010. Global water crisis and future food security in an era of climate change. Food policy, 35(5), pp.365-377.

Marmesat, S., Morales, A., Velasco, J. and Dobarganes, M.C.2012. Influence of fatty acid composition on chemical changes in blends of sunflower oils during thermoxidation and frying. Food chemistry, 135(4), pp.2333-2339.

Nejat, P., Jomehzadeh, F., Taheri, M.M., Gohari, M. and Majid, M.Z.A. 2015. A global review of energy consumption, $\mathrm{CO} 2$ emissions and policy in the residential sector (with an overview of the top ten $\mathrm{CO} 2$ emitting countries). Renewable and sustainable energy reviews, 43, pp.843-862.

Oyerinde, A. Y. and Bello, E. I. 2016. 'Use of Fourier Transformation Infrared ( FTIR ) Spectroscopy for Analysis of Functional Groups in Peanut Oil Biodiesel and Its Blends', 13(3), pp. 1-14. doi: 10.9734/BJAST/2016/22178. 
Pathak, R.K. and PEREIRA, D.N.E., 2016. Various sources for production of biodisel. I Control Pollution, $27(2)$.

Ramana, M. M. Vanta M. 2014. Research Article Silica Sulphuric Acid: An Efficient Reusable, Heterogeneous Acidic Media for Synthesis of Flavones (2-aryl-4H-chromen-4-one) by Cyclocondensation of ohydroxyphenyl aryl-1, 3- propanediones', 25(37), pp. 202-204.

Ribeiro R, Tera A., and Lalo K. 2014. Characterization of Different Oil Soapstocks and Their Application in the Lipase Production by Aspergillusniger under Solid State Fermentation', 2(9), pp. 561-566. doi: 10.12691/jfnr-2-9-6.

Shah, K. A. and Laviree T. 2014. Fatty Acid Methyl Ester Production from Acid Oil Using Silica Sulfuric Acid : Process Optimization and Reaction Kinetics, 68(4), pp. 472-483. doi: 10.2478/s11696-013-0488-4.

Smol, M., Kulczycka, J., Henclik, A., Gorazda, K. and Wzorek, Z. 2015. The possible use of sewage sludge ash (SSA) in the construction industry as a way towards a circular economy. Journal of Cleaner Production, 95, pp.45-54. 